\title{
MONTI, A COMMITMENT TO RIGOUR AND PLURALITY
}

\author{
Javier Franco Aixelá \\ University of Alicante
}

This is the founding issue of MonTI, the academic journal in which the three public universities offering a university degree in Translation and Interpreting in the Valencia region of Spain (Universitat Jaume I, Universitat de València and Universidad de Alicante) wish to provide an open, rigorous, multilingual forum for our discipline.

The name MonTI was chosen a little like the term "impressionism" was for painting, half seriously, half jokingly. This acronym has the virtue of representing the name of the journal in its five main languages: Monographs in Translation and Interpreting, Monografías de Traducción e Interpretación, Monografies de Traducció i d'Interpretació, Monographies de Traduction et d'Interprétation, Monographien zur Translation (true, in German it does not work so well, but nobody's perfect). It is also a name with amusing connotations which seem appropriate to us, since we would like to combine rigour with tolerance and shun pedantry. Somehow, the humorous connotations of our name are the (post?)modern version of the skull which monks of yore, Jerome included, used to remember their mortality. In our case, it reminds us of the need to be extremely serious but without taking ourselves too seriously. If we make it on both counts, we will have a right to feel satisfied.

In the last twenty years, an incredible number of new translation and interpreting journals have been launched by commercial publishers and universities, both in Spain and abroad, which would seem to prove the strength of our (inter)discipline. In our case, we have attempted to create a journal on the basis of a clear identity, as well as to give it visibility through a special con- 
cern for quality. It is an aspiration still to be achieved, but we can guarantee that there will be no lack of enthusiasm and commitment to meet these aims.

To be more specific, the essential characteristics that will define our journal are: internationalism, plurality, rigour and internal democracy.

Internationalism in our journal will rest on three pillars: multilingualism, electronic publication and accessibility.

Firstly, we believe that one of the main deficiencies in most journals we know is to be found in their linguistic limitations. This, we believe, is understandable for operational reasons, but it is also especially to be regretted in a field like translation studies, which by its very nature is multilingual. Constraining our authors to English would involve inhibiting the creativity of many, not to mention that for many others it would be a demand difficult to meet. Limiting our journal to our two official languages, Catalan and Spanish, would worsen these same constraints. At the same time, we try not to be too naive and are aware that English is the current lingua franca of science, so that if our articles are not in English they will reach a much smaller readership, paradoxically contradicting our aim of internationalism. With all this in mind, we have reached the conclusion that articles in MonTI should always be in English plus any other language chosen by the author. For obvious financial reasons, it would be very expensive to provide bilingual versions in the hardcopy journal, but MonTI will also be published as an electronic journal, where space is not a money problem. Thus, in the electronic version we commit ourselves to doing our utmost to translate all articles into English if they are not already written in that language, while also giving all authors the chance to publish a version of their articles in any language they wish. In the hardcopy version, which will be launched six months before the electronic one, we have tried to promote multilingualism and decided to accept five languages: Catalan, English, French, German and Spanish. These particular five languages were chosen because they are the five major languages studied in our degrees and finding peer reviewers if we widened the range of possible languages would be difficult. As a demonstration of this commitment, the website of our journal, with all the information, calls for papers and instructions for authors is available in these five languages. The English version is available at: http://www.ua.es/en/dpto/trad.int/publicaciones/index.html

The electronic mode we have just mentioned is also a commitment to internationalism in itself. We have not forsaken the hardcopy version because we believe in the warmth of the printed word and because we would like to be present in university libraries and on the shelves of the readers who choose to do us this honour. Nevertheless, we know that not to take advantage of the 
astounding disseminating capacity of the Internet would be a serious mistake if we really wish all interested parties to read the contributions of MonTI to the study of translation and interpreting. To fulfil this goal of international accessibility, the Internet version will be open and free for all, and will be published in an institutional space, RUA (Repository of the University of Alicante), ensuring its stability. Furthermore, as already noted above, electronic publication provides multilingual chances that must be taken advantage of in a translation and interpreting journal such as ours.

The second main characteristic of MonTI is its ideological plurality. In order to meet this aim, we will not allow our journal to be a unique or privileged platform of expression for the scholars working in our three universities. We would like, in fact need, articles in MonTI to come from all over the world and cover a range of perspectives providing a comprehensive insight into the attitudes towards our discipline from all academic lines of thought. In fact, we can categorically say that at least $75 \%$ of our original articles will be written by authors not working at our three universities. As a token of this commitment to plurality both regarding authorship and internationalism, issue 1 of MonTI features articles from Germany, Spain, the United Arab Emirates, the United States and France.

To this plurality in authorship we wish to add editorial plurality. We will try to ensure that all issues are edited by at least one expert not working at any of our universities. Thus, issue 1 is co-edited by a scholar from the University of Salamanca (Spain), issue 2 will be co-edited by an expert from the University of Vigo (Spain), and issue 3 will also be co-edited by a professor from the University of Ottawa (Canada). Since editors are completely in charge of designing each issue, including an editorial article providing a global introduction to the matter dealt with in that volume, we think that this combination of approaches will strengthen the polyphonic nature of our journal. Also, we are sure that the presence of a renowned co-editor will enable us to have a much deeper and more complete view of each topic.

Apart from the selection of leading specialists for the edition of each issue, the rigour we aspire to will be guaranteed by an anonymous peer-review process meeting all international recommendations.

Regarding the selection of peer reviewers, we have tried to involve as many prestigious researchers as possible in our project. Jointly, the six members of the Editorial Board have suggested over 80 external assessors whose names are on the journal's website. Together with this Board of Referees, there is a Board of Advisors made up of eminent researchers whose job is to provide strategic recommendations enabling us to constantly improve the quality of 
the journal. Of course, we believe that all members deserve to be on both boards but we know that there are many more who also deserve to be there and are still to be contacted. We hope to extend these lists so that they become more and more representative of research in translation studies. As a further guarantee of transparency, the list of reviewers and advisors is also available on our website, and we will publish the names of all referees acting in each issue.

The selection process will begin with each issue being filtered by the editors, mainly to ensure the topical appropriateness of every contribution. Next, every article will be sent to two experts in the topic, who will deliver their own judgement and recommendations. When both assessments coincide, they will be unappealable. In this connection, we can say that for this first issue seven articles have been selected out of a total of thirteen contributions. We hope that in the future rejections will be fewer and fewer thanks to the increasing quality of the proposals. In any case, from MonTI we will always insist on honestly and rigorously ensuring the quality of all our articles.

In this respect, in order to maintain scholarly depth, MonTI will be made up of only monographs. A first important reason for this decision is that we think it is the only way to make the most of the experience and expertise of the editors. The Editorial Board will attempt to focus each issue on a matter that is really relevant for translation studies. Apart from this founding issue addressing translation studies critically and globally, we have also launched the next two calls for papers, which may be found on our website and deal with Applied Sociology in Translation Studies and Women and Translation respectively.

We also think that the monographic mode will enhance plurality because the same academic space will necessarily provide different views on the same matter. This should enable us to provide a comprehensive, polyphonic insight, much more enriching than the mere accumulation of articles with no clear relationship.

The fourth and last pillar on which the journal is based is internal democracy. All details can be found in the Bylaws section of our website. Suffice it here to comment that, firstly, both the Managing Board of MonTI and the Editorial Board, made up of scholars from our three universities, are appointed on a rotation basis. At the same time, we will guarantee experience by renewing only half of the Editorial Board at most each time. Secondly, it is important to mention here that all substantial decisions, such as the choice of members of all boards, the topic covered by each issue or the editors thereof, 
will always be collective. Once again, we hope that this will strengthen the plurality, openness and transparency of MonTI.

Finally, the Editorial Board of MonTI wishes to express its most sincere thanks for the constant support received by our three universities, and for the selfless collaboration of the members of the various boards who have shown their faith in this project. We hope they will not be disappointed and that this and subsequent issues will make us all feel justly proud and bring about a solid contribution to the world of translation and interpreting.

The best presentation of a journal is its contents. Here is our journal, your journal. Judge for yourselves. 